\title{
Desenvolvimento sustentável, crescimento econômico e o princípio da solidariedade intergeracional na perspectiva da justiça ambiental
}

\author{
Sustainable development, economic growth and the principle of intergenerational \\ solidarity in the perspective of environmental justice
}

\begin{abstract}
Mary Lúcia Andrade Correia ${ }^{1}$ e Eduardo Rocha Dias $^{2}$
1 Advogada, Doutoranda em Direito Constitucional pela UNIFOR; Mestra em Desenvolvimento e Meio Ambiente pela Universidade Federal do Ceará - UFC; Especialista em Direito Ambiental - UECE, Professora de Direito Ambiental da Graduação e Pós-Graduação - UNIFOR; coordenadora do Curso de Especialização em Direito Ambiental - UNIFOR, Brasil. E-mail: maryandrade@unifor.br

2 Doutor em Direito pela Universidade de Lisboa. Professor do Programa de Pós-Graduação em Direito Constitucional da Universidade de Fortaleza - UNIFOR. Procurador Federal, Brasil. E-mail: eduardordias@hotmail.com
\end{abstract}

RESUM 0: Este artigo tem por objeto analisar o desenvolvimento sustentável, crescimento econômico e o princípio da solidariedade intergeracional na perspectiva da Justiça Ambiental, cuja importância consiste em compreender a relevância da temática no cenário atual. Como objetivo geral, a pesquisa visa a demonstrar a importância da conciliação do desenvolvimento sustentável e do crescimento econômico como desafio no século XXI. Como resultados, demanda-se evidenciar a contribuição do desenvolvimento sustentável, aliado ao crescimento econômico, na estratégia de planejamento territorial e no uso dos recursos naturais, visando à sustentabilidade, bem como refletir sobre 0 desenvolvimento sustentável no contexto brasileiro.

Palavras-chave: Desenvolvimento sustentável. Crescimento econômico. Solidariedade Intergeracional. Responsabilidade. Justiça ambiental.

\begin{abstract}
This article has as main objective to analyze sustainable development, economic growth and the principle of intergenerational solidarity in the context of environmental justice, whose importance is to understand the relevance of the topic in the current scenario. As a general objective, the research aims to demonstrate the importance of conciliation of sustainable development and economic growth as a challenge in the 21st century. As a result, the demand tries to show the contribution of sustainable development, with the economic growth, in territorial planning strategy and the use of natural resources, aiming the sustainability, as well as reflect on sustainable development in the Brazilian context.
\end{abstract}

Keywords: Economic growth. Intergenerational Solidarity. Liability. Environmental justice.

Sumário: 1 Introdução - 2 Desenvolvimento sustentável e crescimento econômico como desafio no Século XXI - 30 desenvolvimento sustentável e o princípio da solidariedade intergeracional - 4 Desenvolvimento sustentável e o desafio da economia verde - 5 Considerações Finais - Referências.

Planeta Amazônia: Revista Internacional de Direito Ambiental e Políticas Públicas 


\section{INTRODUÇÃO}

0 desenvolvimento sustentável surgiu na década de 1980, no Relatório Brundtland, também intitulado Nosso Futuro Comum ou Our Common Future. 0 documento traz pela primeira vez a definição de desenvolvimento sustentável, sugerindo como mudança de enfoque a conciliação entre conservação da natureza e crescimento econômico (CM M AD, 1991). O Relatório Brundtland resultou da pesquisa da Comissão Mundial para o Meio Ambiente e Desenvolvimento, cujo objetivo foi pesquisar os problemas ambientais em uma perspectiva global.

A expressão desenvolvimento sustentado surgiu como novo conceito, pautado em uma concepção que busca compatibilizar o desenvolvimento com a economia, envolvendo variáveis de ordem econômica, social e ambiental, indicando um caminho a ser seguido pelos países desenvolvidos e em desenvolvimento. A problemática ambiental e o modelo econômico apontam para a necessidade de modelo diferente de crescimento que possibilite a promoção do desenvolvimento com a redução da pobreza e mais equidade socioambiental. Relacionado ao conceito de desenvolvimento sustentável, há as acepções de sustentabilidade com vários conceitos, por exemplo, a acepção de sustentabilidade com suporte na racionalidade econômica, economia ecológica, ambiental, política etc., o que denota a dificuldade apenas de uma definição para sustentabilidade. Não constitui, no entanto, objeto da investigação abordar todos esses conceitos de sustentabilidade relacionados ao desenvolvimento sustentável.

Do ponto de vista socioambiental, compatibilizar meio ambiente, crescimento e desenvolvimento econômico significa considerar os problemas ambientais no âmbito continuum de planejamento, atendendo-se adequadamente às exigências de ambos, observandose as inter-relações particulares a cada contexto político, sociocultural, econômico e ecológico numa dimensão tempo/espaço. Assim sendo, a política ambiental não deve se erigir em obstáculo ao desenvolvimento, mas sim em um de seus instrumentos, ao propiciar a gestão racional dos recursos naturais, que constituem a base material de sustentabilidade.

Como objetivo geral, a pesquisa visa a demonstrar a importância da conciliação do desenvolvimento sustentável e do crescimento econômico ressaltando o princípio da solidariedade intergeracional como elemento fundamental na realização da Justiça Ambiental. Especificamente, se tenciona verificar o desenvolvimento sustentável e o crescimento econômico, levando em consideração o princípio da solidariedade intergeracional; e, ainda, demonstrar a necessidade da mudança de paradigma do crescimento com sustentabilidade de forma solidária no enfrentamento dos problemas ambientais.

A metodologia utilizada na pesquisa consiste na análise exploratória e descritiva sobre o objeto de estudo, por meio de levantamento bibliográfico, livros, documentos eletrônicos, teses, dissertações, revistas e outros periódicos etc.

Como resultados, demanda-se evidenciar a contribuição do desenvolvimento sustentável e do crescimento econômico como estratégia de planejamento territorial no uso dos recursos naturais visando à sustentabilidade e sua utilização pelas gerações vindouras, bem 
como, refletir sobre o desenvolvimento sustentável no contexto brasileiro.

\section{DESENVOLVIM ENTO SUSTENTÁVEL E CRESCIM ENTO ECONÔM ICO COMO DESAFIO NO SÉ- CULO XXI}

Desde os primórdios, o homem estabelece relações com a natureza de várias formas consoante o seu interesse e suas necessidades. Essa relação intensificou-se ao longo da história da humanidade, resultando em ações que desencadeiam efeitos negativos e positivos no meio ambiente. 0 surgimento da crise ambiental e a má gestão no uso dos recursos naturais limitados ou bens finitos voltados para satisfação das necessidades ilimitadas e infinitas do ser humano acarreta a possibilidade de conflitos ambientais na atualidade. Assim, acentua Milaré (2013, p.228) a ideia de que

De fato a possibilidade de conflitos tende a aumentar, já que o mundo, depois de ter se defrontado com a crise do petróleo na segunda metade do século XX, prepara-se agora - com o crescimento inevitável da população e a impostergável necessidade de redução da pobreza - para enfrentamento de situação muito mais sombria, com mais degradação do solo, mais desertificação, mais crise da água, perda da biodiversidade etc, sem falar em agravamento das mudanças climáticas.

Na realidade a crise ambiental se estabeleceu em virtude da não preocupação do homem com a natureza, do estabelecimento da visão e ação antrópicas, sem dimensionamento das consequências dos efeitos sobre o estoque de capital natural e sobre o próprio homem.

Ante tantos desafios, surge a necessidade de mudança de estratégia na convivência do homem com a natureza, daí a importância do conceito de desenvolvimento sustentável como novo caminho a ser trilhado. Tal ideia é aplicada em diversos contextos, a exemplo projetos, mídia, políticas públicas, academia etc. Em conformidade com Kronemberger (2011, p. 17), após 1950, o termo "desenvolvimento" foi associado a distintas concepções, como a de crescimento econômico, ecodesenvolvimento, desenvolvimento sustentável, governança global [....]. 0 desenvolvimento, para Becker (2008, p. 103), tem caráter antagônico, porquanto, "ao mesmo tempo em que é desenvolvimento para uns, é não desenvolvimento para outros". E, ainda, anota Becker, que ao mesmo tempo em que o desenvolvimento produz o enriquecimento de uns poucos, provoca o empobrecimento de muitos outros. Ressalta-se que o modelo de desenvolvimento convencional em fins da década de 1960, passou a diminuir sua força com as preocupações ambientais crescentes, e a intensificação da poluição em escala global assinalou um novo marco na história - 0 da proteção ambiental.

Com efeito, explica Kronemberger (2011, p. 20), os debates em torno dos temas ecológicos aprofundaram-se ainda mais na década de 1970, em razão do maior conhecimento sobre a dinâmica dos ecossistemas e riscos de acidentes nucleares e outros [...]. Desde a década de 1980 se procura empregar o termo desenvolvimento sustentável como paradigma no estabelecimento da relação entre sociedade e natureza de forma bem mais integrada, sendo que, na prática o homem ainda não alcançou este desafio. 
Hodiernamente, não há um consenso sobre a definição de desenvolvimento sustentável, embora a definição mais utilizada seja a contida no Relatório Brundtland. Para Kronemberger (2011, p. 20), as definições conservam sempre a ideia de pacto intergeracional, e a necessidade de se pensar no uso do território e dos recursos naturais a médio e longo prazos entre as várias gerações.

Outra perspectiva acerca do desenvolvimento está contida na definição de Desenvolvimento Sustentável do documento Our Common Future ou, como é conhecido, Relatório Brundtland (1991, online), como o processo que "satisfaz as necessidades presentes, sem comprometer a capacidade das gerações futuras de suprir suas próprias necessidades". No entendimento de Buarque (2002, p. 58), o desenvolvimento sustentável "se difunde como uma proposta de desenvolvimento diferenciada" demandando novas concepções e percepções organizando "uma nova postura da sociedade diante dos desafios do presente e do futuro". Como acentua M orin e Terena $(2001$, p. 9) a sustentabilidade do desenvolvimento é um problema complexo, porque a sua essência está imbricada em um tecido de problemas inseparáveis, exigindo uma reforma epistemológica da própria noção de desenvolvimento.

Portanto, o desenvolvimento sustentável pressupõe mudanças duradouras na economia e na sociedade na solução dos desafios atuais. A expressão desenvolvimento sustentável é por demais, utilizada, mas, até que ponto essa concepção realmente é levada a sério pelos setores da sociedade e da economia? É difícil a resposta a essa indagação, pois, em alguns casos, a utilização da terminologia do desenvolvimento sustentável é empregada por empreendedores apenas formalmente, haja vista o fato de que, conforme Milaré (2013, p. 67), se utilizam da leniência de órgãos ambientais licenciadores e fiscalizadores (que, conscientes ou não, às vezes cedem a pressões políticas ou econômicas) compondo um quadro preocupante. Assevera, ainda, o autor que, "nesses casos o "desenvolvimento sustentável" é uma falácia, um engodo ambiental". Na realidade o conceito de desenvolvimento, na lição de Milaré (2013, p. 67), "transcende 0 de simples crescimento econômico, de modo que a verdadeira alternativa excludente está entre desenvolvimento integral harmonizado e mero crescimento econômico".

No entendimento de Rodrigues (2012, p. 154), o desenvolvimento é condição necessária para o crescimento econômico, no entanto, este fato não está muito claro ainda na maioria das cabeças desenvolvimentistas. No início do século XX, Sachs $(2002$, p. 15) já apontava para a importância da natureza e da essencialidade de encontrar harmonia entre o processo produtivo, que fosse capaz de incorporar a natureza como valor. Assim, a diferença entre crescimento econômico e desenvolvimento é ressaltada por Veiga (2010, p. 82), para quem "o crescimento econômico, tal qual o conhecemos, vem se fundando na preservação dos privilégios das elites que satisfazem seu afã de modernização; já o desenvolvimento se caracteriza pelo seu projeto social subjacente".

Já Rodrigues (2012, p.157) acentua que "o crescimento econômico é um meio para expandir as liberdades, as quais dependem de outros determinantes, como educação, saúde e direitos civis". Enquanto isso, para o autor, o projeto social subjacente referido por Veiga é 0 garantidor do desenvolvimento humano. O desenvolvimento, para Nusdeo (2005, p. 354), 
envolve uma série infindável de modificações de ordem qualitativa e quantitativa, de tal maneira a conduzir a uma radical mudança de estrutura da economia e da própria sociedade, do País. Para o autor, essas mudanças quantitativamente expressas revelam alterações de natureza qualitativa, inclusive de ordem psicológica, cultural e política.

Portanto, a diferença entre desenvolvimento e crescimento na compreensão de Nusdeo (2005, p. 355) consiste no fato de que este último é apenas o crescimento da renda e do Produto Interno Bruto - PIB, no entanto, sem implicar ou trazer mudança estrutural mais profunda. Neste sentido, M iller (2007, p.6) acentua que o crescimento econômico normalmente é medido pela mudança percentual no Produto Interno Bruto de um país e corresponde aos bens e serviços produzidos por todas as empresas e organizações nacionais e estrangeiras nesse Estado. Ressalta, ainda, 0 autor que "as mudanças no crescimento econômico de um país por pessoa são medidas pelo PIB per capita: o PIB dividido pela população total no meio do ano".

0 desenvolvimento econômico é, para Miller $(2007$, p.6) a melhoria dos padrões de vida dos seres humanos proporcionada pelo crescimento econômico. Neste sentido, o modelo de produção dominante, esclarece Dantas (2014, p. 318), é baseado no crescimento e produziu exclusão social em decorrência da concentração de renda e degradação ambiental, em função da incessante busca de matérias-primas para a produção. Segundo o autor, por meio da tecnologia, buscava-se produzir mais em menor tempo, pois o crescimento econômico se importava apenas com o aumento do PIB (Produto Interno Bruto), ou seja, somente a medição do aspecto econômico era relevante.

No Brasil, a Lei no. 6.938/81, que dispõe sobre a Politica Nacional do M eio Ambiente (PNMA), positivou o Princípio do Desenvolvimento Sustentável além das diretrizes para formulação de políticas públicas e instrumentos da gestão ambiental, como um marco na história da proteção ambiental, e trouxe também como objetivos a harmonização da economia e meio ambiente em seu art. $2^{\circ}$, da PNM $A^{1}$.

Posteriormente, a Constituição Federal de 1988 recepcionou a Lei da Política Nacional do M eio Ambiente e trouxe princípios importantes da Política Global do Meio Ambiente, como, por exemplo, o Princípio do Desenvolvimento Sustentável, esculpido no caput do art. 225 do Texto Constitucional ${ }^{2}$. Assim, busca-se, com o desenvolvimento sustentável, na lição de Fiorillo (2011, p.83), a coexistência harmônica entre economia e meio ambiente. Permite-se 0 desenvolvimento, mas de forma sustentável, planejada, para que os recursos não se esgotem ou se tornem inócuos. Nesta perspectiva, o Princípio do Desenvolvimento Sustentável tem por conteúdo, conforme Fiorillo (2011, p. 83) a manutenção das bases vitais da produção do homem e de suas atividades, garantindo igualmente uma relação satisfatória entre os homens e destes com o seu ambiente [...]. Por isso a importância da mudança de paradigma no

\footnotetext{
${ }^{1}$ Art. 2․ . A Política Nacional do M eio Ambiente tem por objetivo a preservação, melhoria e recuperação da qualidade ambiental propícia à vida, visando assegurar, no País, condições ao desenvolvimento socioeconômico, aos interesses da segurança nacional e à proteção da dignidade da vida humana. (Art. 2ํda Lei n. 6.938/81).

${ }^{2}$ Art. 225. Todos têm direito ao meio ambiente ecologicamente equilibrado, bem de uso comum do povo e essencial à sadia qualidade de vida, impondo-se ao Poder Público e à coletividade o dever de defendê-lo e preservá- lo para as presentes e futuras gerações.
}

Planeta Amazônia: Revista Internacional de Direito Ambiental e Políticas Públicas 
que se refere à forma de agir, interferir e interagir do homem com o meio ambiente.

Na concepção do Fiorillo (2011, p. 90), o ponto de equilíbrio entre o desenvolvimento social, o crescimento econômico e a utilização dos recursos naturais exigem um adequado planejamento territorial que tenha em conta os limites da sustentabilidade. 0 critério de desenvolvimento sustentável, na compreensão de Sardenberg $(1995$, p. 3), deve valer tanto para o Território Nacional na sua totalidade, áreas urbanas e rurais, como para a sociedade, para o povo, respeitadas as necessidades culturais e criativas do País. Não resta dúvida de que a preservação ambiental e o desenvolvimento econômico são fundamentais no contexto atual da sociedade e devem ser conciliados visando à sustentabilidade.

O legislador constituinte de 1988, ao tratar sobre a ordem econômica, no art. 170, VI3, trouxe o Princípio da Defesa do Meio Ambiente como forma de assegurar a vida com qualidade. Portanto, com origem no texto constitucional, a liberdade econômica e a livre iniciativa devem coexistir como direito fundamental ao meio ambiente ecologicamente equilibrado, sem que um anule o outro. A atividade econômica deve ser realizada dentro dos parâmetros ambientais, de forma que os danos ao ambiente sejam minimizados e a qualidade ambiental assegurada. Para Henz et al (2012, p. 96), o escopo da Economia, do Direito e das políticas públicas, ao menos no plano do dever ser, é o mesmo: constituir uma sociedade justa, solidária e de respeito à dignidade da vida. Asseveram, ainda, os autores que as tensões entre crescimento, distribuição e conservação ganham novos significados com base em critérios qualitativos de desenvolvimento, que incluem a dimensão ambiental como um aspecto indissociável da qualidade de vida.

\section{DESENVOLVIMENTO SUSTENTÁVEL E 0 PRINCÍPIO DA SOLIDARIEDADE INTERGERACIO- NAL}

O desenvolvimento sustentável, como paradigma a ser alcançado pelos países desenvolvidos e em desenvolvimento, deve considerar, além da dimensão ambiental, aspectos econômicos e sociais, conforme explicitado em passagem anterior deste texto. A discussão em torno do desenvolvimento sustentável deve considerar o fato de que, atualmente, há vários países em desenvolvimento que possuem dificuldade de acesso a saúde, educação, emprego e, ainda, aqueles que não possuem alimentação adequada e condições de vida digna. Assim, deverá a dimensão multidimensional do desenvolvimento sustentável estar em consonância com as necessidades nos vários contextos - socioeconômico, ambiental, político e cultural. No entendimento de Sachs (2004, p. 15-16), o desenvolvimento sustentável está estruturado em cinco pilares:

\footnotetext{
${ }^{3}$ Art. 170. A ordem econômica, fundada na valorização do trabalho humano e na livre iniciativa, tem por fim assegurar a todos existência digna, conforme os ditames da justiça social, observados os seguintes princípios:

[...]

$\mathrm{VI}$ - defesa do meio ambiente, inclusive mediante tratamento diferenciado conforme o impacto ambiental dos produtos e serviços e de seus processos de elaboração e prestação.
}

Planeta Amazônia: Revista Internacional de Direito Ambiental e Políticas Públicas 
a) Social: fundamental por motivos tanto intrínsecos quanto instrumentais, uma vez que diferenças sociais existem de forma ameaçadora sobre muitos lugares problemáticos do planeta, inclusive no Brasil;

b) Ambiental: sistema de sustentação da vida como provedor de recursos e como "recipiente" para a disposição de resíduos (muitas vezes produzidos desnecessariamente);

c) Territorial: relacionado à distribuição espacial dos recursos, das populações e das atividades;

d) Econômico: sendo a viabilidade econômica indispensável a um país;

e) Política: a democracia é um valor fundamental e um instrumento necessário para fazer as coisas acontecerem.

Para que ocorra a inclusão social, Sachs considera que deve existir os cinco pilares no desenvolvimento sustentável. Assevera o autor que "a promoção de meios de vida sustentáveis deve se tornar parte da linha mestra da estratégia de desenvolvimento e não pode ter sucesso sem a participação dos grupos e das comunidades locais". Logo, o desenvolvimento sustentável deve ter a participação da sociedade, comunidade e planejamento territorial, visando ao equilíbrio entre a economia e o meio ambiente. Países em desenvolvimento, na análise de Romeiro (2012, p. 73), possuem especificidades que precisam ser tratadas com políticas específicas, tais como grandes contingentes populacionais, vivendo, ainda, de atividades florestais e da pequena agricultura de subsistência.

Assim, a relação do homem com a natureza e com o seu entorno, na dimensão ambiental, econômica, social e cultural, precisa ser pensada de forma articulada, tendo por finalidade a manutenção das condições de vida na Terra. As questões cruciais, no entanto, segundo ressalta Hansen (1999, p. 63), como o desperdício, ocupação desordenada da área urbana, crescimento populacional desequilibrado, conflito e violência, pobreza e miserabilidade, degradação ambiental, educação precária [...], devem ser enfrentados no desenvolvimento sustentável. Assinala, ainda, o autor que a obtenção de lucros não pode ser justificativa para a destruição ambiental nem para o esgotamento dos recursos naturais. Há, portanto, que se ter o equilíbrio, bem como mudança e reestruturação de concepções e conceitos que possibilitem na prática a formação de uma sociedade mais justa e solidária.

0 constituinte, ao inserir o meio ambiente como direito fundamental da pessoa humana, reconheceu o Princípio do Desenvolvimento Sustentável, para que ocorra a melhoria da qualidade de vida, bem como o Princípio da Solidariedade Intergeracional, como pressuposto do que está por vir. Na concepção de M ilaré (2013, p. 259), o Princípio da Solidariedade Intergeracional visa a assegurar a solidariedade da presente geração em relação às futuras, para que estas possam usufruir, de forma sustentável, dos recursos naturais.

Lembre-se que, no ordenamento jurídico brasileiro, a solidariedade está na Constituição Federal de $1988^{4}$, Art. 3ํ, como fundamento do Estado Democrático de Direito, justificando, assim, a finalidade do Direito Ambiental e coadunado com a proposta do Direito Intergeracional. No Brasil de maneira sui generis, a Constituição Federal confere ao Princípio da

\footnotetext{
${ }^{4}$ Art. 3‥ Constituem objetivos fundamentais da República Federativa do Brasil: I - construir uma sociedade livre, justa e solidária.
}

Planeta Amazônia: Revista Internacional de Direito Ambiental e Políticas Públicas 
Solidariedade Intergeracional algo que, até então, era tratado com certa cautela, no entanto, com as frequentes discussões e quase sempre relacionada à sustentabilidade ambiental, 0 tema se tornou evidente, considerando a perspectiva de conceder às próximas gerações as mesmas benesses ambientais do presente. Compreende, com razão, M ilaré $(2013$, p.259) que "a importância do preceito avulta ante a constatação de que a generosidade da terra não é inesgotável, e do fato de que já se está consumindo cerca de $30 \%$ além da capacidade planetária de suporte e reposição".

Nesta perspectiva, a titularidade ao meio ambiente ecologicamente equilibrado no Texto Constitucional de 1988 é de responsabilidade do Estado e da coletividade, sendo assegurada para as futuras gerações. A Declaração de Estocolmo sobre M eio Ambiente Humano (1972, online) trouxe em seus princípios 2 e 5 a preocupação com as futuras gerações,

\begin{abstract}
Princípio 2 - Os recursos naturais da Terra, incluídos o ar, a água, o solo, a flora e a fauna e, especialmente, parcelas representativas dos ecossistemas naturais, devem ser preservados em benefício das gerações atuais e futuras, mediante um cuidadoso planejamento ou administração adequada.

Princípio 5 - Os recursos não renováveis da Terra devem ser utilizados de forma a evitar o perigo do seu esgotamento futuro e a assegurar que toda a humanidade participe dos benefícios de tal uso.
\end{abstract}

Na Segunda Conferência das Nações Unidas sobre M eio Ambiente e Desenvolvimento, no Rio de Janeiro (1992, online), foi também reafirmado o Princípio da Solidariedade Intergeracional em escala global em seu princípio 3, que expressa: "0 direito ao desenvolvimento deve ser exercido de modo a permitir que sejam atendidas equitativamente as necessidades de gerações presentes e futuras".

Como se percebe nos princípios das Declarações e na Constituição Federal de 1988, está explicita a preocupação em assegurar, por meio da solidariedade intergeracional, o meio ambiente e as condições de vida de forma equitativa entre as presentes e futuras gerações. Ressalta Milaré (2013, p. 260) "que a solidariedade humana - entre as pessoas e destas para com o Planeta - é uma fonte do saber e agir". Acentua, ainda, o autor a ideia de que a solidariedade, como valor natural cultivado, é fonte para a Ética e para o Direito. O Princípio da Solidariedade ou Equidade Intergeracional, na acepção de Silva (2011, p. 124), "decorre do reconhecimento constitucional e internacional do direito das futuras gerações ao meio ambiente ecologicamente equilibrado e, portanto, a imposição a todos, seja ao Estado, seja à coletividade, do dever de garanti-lo".

Sobre a solidariedade, ressalta Costa $(2010$, p.59) que, como o próprio nome indica, 0 princípio decorre do sentimento de solidariedade que os indivíduos devem ter para com os outros, mesmo que estes ainda não tenham existência. O Supremo Tribunal Federal acolheu o princípio da solidariedade intergeracional como demonstra a Ação Direta de Inconstitucionalidade - ADI 3.540-MC de 2005, de relatoria do ministro Celso de M elo, em que reconhece a solidariedade no caso de supressão de vegetação de área de preservação permanente. Conforme STF (ON-LINE, 2006), eis o seguinte teor na Ementa, 
Meio ambiente - Direito à preservação de sua integridade (CF, art. 225) - Prerrogativa qualificada por seu caráter de metaindividualidade - Direito de terceira geração (ou de novíssima dimensão) que consagra o postulado da solidariedade - Necessidade de impedir que a transgressão a esse direito faça irromper, no seio da coletividade, conflitos intergeracionais - Espaços territoriais especialmente protegidos ( $C F$, art. $225, \S 1$, III) - Alteração e supressão do regime jurídico a eles pertinente - Medidas sujeitas ao princípio constitucional da reserva de lei - Supressão de vegetação em área de preservação permanente - Possibilidade de a administração pública, cumpridas as exigências legais, autorizar, licenciar ou permitir obras e/ ou atividades nos espaços territoriais protegidos, desde que respeitada, quanto a estes, a integridade dos atributos justificadores do regime de proteção especial - Relações entre economia (CF, art. 3ㅇ, II, C/ C 0 art. 170, VI) e ecologia (CF, art. 225) - Colisão de direitos fundamentais - Critérios de superação desse estado de tensão entre valores constitucionais relevantes - Os direitos básicos da pessoa humana e as sucessivas gerações (fases ou dimensões) de direitos (RT) 164/158, 160-161) - A questão da precedência do direito à preservação do meio ambiente: uma limitação constitucional explícita à atividade econômica (CF, art. 170, VI) - Decisão não referendada - consequente indeferimento do pedido de medida cautelar. A preservação da integridade do meio ambiente: expressão constitucional de um direito fundamental que assiste à generalidade das pessoas. (ADI 3.540-M C, Rel. M in. Celso de M ello, julgamento em 1--9-2005, Plenário, DJ de 3-2-2006.)

No teor da Ementa, percebe-se o reconhecimento do Princípio da Solidariedade Intergeracional pelo Supremo Tribunal Federal. Isto significa a responsabilidade da sociedade atual com as futuras gerações e com o direito daqueles que estão por vir na perspectiva do desenvolvimento sustentável. Neste sentido, a solidariedade demonstrada e praticada pela sociedade vigente tem por finalidade assegurar o meio ambiente saudável e sua devida fruição para as gerações vindouras, passando necessariamente pela Justiça Ambiental.

A expressão Justiça Ambiental, na concepção de Rammê (2012, p. 13), remonta aos movimentos sociais dos Estados Unidos que, em 1960, passaram a reivindicar direitos civis às populações afrodescendentes, desse País, bem como a protestar contra a exposição humana à contaminação tóxica industrial. Na década de 1980, o movimento por Justiça Ambiental estadunidense estava diretamente ligado ao racismo ambiental. Na década de 1990, no entanto, marca a expansão em escala global das lutas por Justiça Ambiental. Atualmente, como informa Rammê (2012, p. 23), o movimento por Justiça Ambiental abarca todos os conflitos socioambientais, cujos riscos sejam suportados de forma desproporcional sobre populações socialmente vulneráveis ou conhecidos como periféricos. No Brasil conforme Londres (2010, online),

A contaminação de ambientes rurais e residenciais e a intoxicação de trabalhadores e populações por agrotóxicos, assim como as disputas por terras, o desemprego e a insegurança alimentar provocados pela expansão do agronegócio constituem graves exemplos de injustiça ambiental e, como não poderia e deixaria de ser, figuram em diversos casos do Mapa de Conflitos envolvendo Injustiça Ambiental e Saúde no Brasil. 
Foi no Brasil criado o Mapa da Injustiça Ambiental como resultado de um projeto desenvolvido em conjunto pela Fundação Oswaldo Cruz (FIOCRUZ) e pela FASE - Solidariedade e Educação, com o apoio do Departamento de Saúde Ambiental e Saúde do Trabalhador do M inistério da Saúde. 0 objetivo maior do projeto, conforme Londres (2010, online), consiste no mapeamento inicial das lutas de inúmeras populações e grupos atingidos em seus territórios por projetos e políticas baseadas numa visão de desenvolvimento insustentável e prejudicial à saúde.

Nesta perspectiva, a Justiça Ambiental busca um tratamento justo e igual para todas as pessoas. A luta por direito de viver um ambiente limpo e saudável é, na acepção de Acselrad (2009, p. 16), um direito que

Inclui o ambiente de trabalho e moradia e, sobretudo, de receber uma proteção ambiental justa e equânime - e que nenhuma pessoa ou grupo social esteja acima da lei. 0 que o movimento dedica-se a fazer é evidenciar o padrão estatístico, onde ocorrem os aterros, incineradores e demais unidades poluidoras quaisquer, documentando por meio de provas como cartas, memorandos ou relatórios oficiais que possam demostrar que estes eventos se deslocam para locais onde a população ofereça menor resistência.

Assim, a solidariedade intergeracional constitui um princípio de fundamental importância na defesa do meio ambiente, pautado na ética e no sentimento de Justiça Ambiental, na medida em que defende a proteção da qualidade de vida para todos de forma equânime.

\title{
4 DESENVOLVIM ENTO SUSTENTÁVEL E O DESAFIO DA ECONOMIA VERDE
}

No contexto atual, a busca da sustentabilidade encontra respaldo nas ideologias intimamente ligadas aos objetivos básicos do desenvolvimento. Ao tratar sobre uma visão operativa do desenvolvimento sustentável, Queirós (2003, p. 334) explica que

\begin{abstract}
Uma primeira orientação expressa que os recursos naturais são prioridade do desenvolvimento sustentável. Esta tradição concentra a sua abordagem no problema da degradação dos recursos e na procura da estabilidade ecológica criticando o paradigma econômico convencional (REES, 1992, REDCLIFT, 1993). Uma outra orientação encara a possibilidade do desenvolvimento sustentável ser compatível com o crescimento econômico (PEPPER, 1996). Esta orientação, para além de reconhecer que o crescimento econômico não está separado do ambiente, centra-se em pressupostos acerca dos recursos não renováveis, limites ao crescimento e escassez potencial, como meios para alcançar o desenvolvimento sustentável (PEARCE et al, 1997).
\end{abstract}

Com efeito, ressalta Queirós, "nem todos que procuram o desenvolvimento sustentável encaram a dimensão ecológica como tendo primazia sobre todos os outros objetivos da humanidade". Assim, o uso dos recursos naturais pela economia é uma realidade, como também a relação entre economia e consumo, pois o que impulsiona a economia é o consumo, sendo com base neste que advém o lucro e assim por diante. 0 conceito de desenvolvi-

Planeta Amazônia: Revista Internacional de Direito Ambiental e Políticas Públicas 
mento sustentável é discutido e aperfeiçoado desde a década de 1970, nos planos nacional e internacional, e constitui a sua implementação definitiva um desafio no século XXI.

Ressalta o Relatório do Instituto de Pesquisa Aplicada - IPEA (2012, online), o fato de ter havido um avanço definitivo na contemplação dos interesses dos países em desenvolvimento alcançado na Segunda Conferência - Rio-92, ocasião em que se consagrou o Princípio das Responsabilidades Comuns, porém diferenciadas (Princípio no 7 da "Declaração do Rio) 5 . Como alcançar, no entanto, os objetivos do desenvolvimento sustentável na atualidade? A economia verde consiste em um desses objetivos e deve ser alcançada em escala global.

A economia verde no contexto do desenvolvimento sustentável será abordada, buscando-se a melhor compreensão do assunto como um dos Objetivos do Desenvolvimento do Milênio (ODM ), estabelecido na Conferencia das Nações Unidas sobre Desenvolvimento Sustentável Rio + 20, realizada nos dias 13 a 22 de junho de 2012, na cidade do Rio de Janeiro, cujo objetivo foi discutir sobre a renovação do compromisso político com o desenvolvimento sustentável. De acordo com o Relatório de Pesquisa IPEA (2012, online),

A Conferência teve como objetivos "assegurar a renovação dos compromissos políticos dos países com o desenvolvimento sustentável, avaliar os progressos alcançados até o momento [...]". A Conferência focou dois temas importantes: o primeiro a economia verde no contexto do desenvolvimento sustentável e erradicação da pobreza e o segundo o marco institucional para o desenvolvimento sustentável (governança internacional).

De tal modo, se inicia outra oportunidade de implementação do desenvolvimento sustentável voltado para a prosperidade, bem-estar e proteção ambiental. Na realidade, foi um evento importante para criação de ideias, análise de soluções e da sustentabilidade, com isso, sendo firmados princípios fundamentais, compromissos essenciais, e traçada nova direção para os países rumo ao desenvolvimento sustentável.

Um dos compromissos renovados na Conferencia Rio +20 foi em relação à economia verde e à erradicação da pobreza no contexto do desenvolvimento sustentável. A importância da economia verde é ressaltada em Hargrave e Paulsen (2012, p. 13) ao afirmar que a finitude dos recursos naturais, os serviços ecossistêmicos e os limites planetários dados pela ciência são levados em consideração e constituem marcos claro dentro dos quais as atividades de produção, distribuição e consumo poderão ter lugar. Asseveram Hargrave e Paulsen (2012, p. 13) que

Os serviços ecossistêmicos, as externalidades ambientais, mudanças climáticas, escassez dos recursos naturais, eficiência energética e Justiça social são levados em

\footnotetext{
${ }^{5}$ PRINCÍPIO 7 - Os Estados devem em um espírito de parceria global, para a conservação, proteção e restauração da saúde e da integridade do ecossistema terrestre. Considerando as distintas contribuições para a degradação ambiental global, os Estados têm responsabilidades comuns porém diferenciadas. Os países desenvolvidos reconhecem a responsabilidade que têm na busca internacional do desenvolvimento sustentável, em vista das pressões exercidas por suas sociedades sobre o meio ambiente global, e das tecnologias e recursos financeiros que controlam. Disponivel em: http://www.scielo.br/pdf/ea/v6n15/v6n15a13.pdf. Acesso em 03 Jan. 15.
}

Planeta Amazônia: Revista Internacional de Direito Ambiental e Políticas Públicas 
consideração e são elementos fundamentais na orientação do comportamento dos agentes no desenvolvimento da economia verde.

A transição da economia convencional para a economia verde é lenta, mas consiste em uma tendência que está se consolidando por meio das necessidades das mudanças regulatórias e por oportunidades de novos negócios em escala global. 0 Brasil, por exemplo, na acepção de Hargrave e Paulsen (2012, p. 13) deveria,

\begin{abstract}
Além de esverdear sua economia, aproveitar estrategicamente características de sua economia que já seguem essa tendência - como é o caso da matriz energética com baixa intensidade de carbono. Se tais aspectos fossem melhor explorados, poderiam trazer um diferencial competitivo para alguns produtos brasileiros no contexto da economia verde.
\end{abstract}

O Programa das Nações Unidas para o M eio Ambiente - PNUM A (2011, online) define economia verde como "uma economia que resulta em melhoria do bem-estar da humanidade e igualdade social, ao mesmo tempo em que reduz significativamente riscos ambientais e escassez ecológica". E, ainda, é considerada uma atividade com baixa emissão de carbono. Assim, a economia verde busca a eficiência no uso dos recursos naturais e a inclusão social. De acordo com o Relatório rumo à economia verde do PNUM A (2011, online), o esverdeamento das economias não é um empecilho ao crescimento, mas constitui novo mecanismo de crescimento; ou seja, uma rede geradora de trabalho digno, que consiste em uma estratégia vital para a eliminação da pobreza persistente. Nesta perspectiva, o desenvolvimento da economia verde e, consequentemente, a renda e o crescimento devem ser estimulados com sustentabilidade, tanto pelo Poder Público como pelo setor privado.

A motivação básica para a difusão do conceito de economia verde, no entendimento de Pinheiro (2012, p. 18), está associada ao diagnóstico de que o atual "paradigma econômico" - apelidado de "economia marrom" - baseado em uma má alocação do capital, está em crise e não se sustentará no longo prazo. Sem dúvida, a eficiência no uso dos recursos naturais pela economia verde é imprescindível e está relacionada ao estabelecimento de padrões e limites no uso dos recursos ambientais, como também, ao emprego de recursos tecnológicos para alcançar maior eficiência.

A crise do modelo convencional da "economia marrom" justifica a necessidade de um novo modelo que leve em consideração o estoque de capital natural e a limitação da capacidade de reposição dos recursos ambientais na Terra. Desta maneira, a economia verde consiste em um novo paradigma econômico rumo ao tão almejado desenvolvimento sustentável. A busca pela sustentabilidade e a mitigação dos danos ao ambiente contribuem para preservação da qualidade de vida, da cidadania e da geração de emprego e renda, o que proporciona melhores condições de vida e Justiça Ambiental.

No entendimento de Pinheiro (2012, p. 19), esse novo paradigma é pautado por investimentos produtivos que resultem em preservação e valorização dos recursos naturais, dos ecossistemas e da biodiversidade planetária. Transformar e alcançar, no entanto, essa transi- 
ção da economia convencional para a economia verde requer um esforço global. Para tanto, serão necessárias mudanças nas estratégias de planejamento territorial, emprego de tecnologias, mudanças de concepções no uso dos recursos naturais e de consumo, amadurecimento das instituições e políticas públicas de incentivo ao desenvolvimento da economia verde com sustentabilidade, investimento em Educação Ambiental propiciando uma consciência ambiental que resulte em maior equilíbrio do meio ambiente. De acordo com o PNUMA (2011, online), no relatório rumo à economia verde, atualmente,

apenas $20 \%$ das reservas populacionais de peixes comerciais, em sua maioria de espécies de baixo preço, são subexploradas; $52 \%$ são totalmente exploradas sem mais espaço para expansão; cerca de $20 \%$ são sobreexploradas e $8 \%$ estão esgotadas. A água está se tornando escassa e há previsão de que o estresse hídrico aumente quando a distribuição de água satisfizer apenas $60 \%$ da demanda mundial em 20 anos. A agricultura teve um aumento de colheitas devido, essencialmente, ao uso de fertilizantes químicos, que reduziram a qualidade do solo e não refrearam a tendência crescente de desmatamento (que continua a 13 milhões de hectares de floresta por ano de 1990-2005). A escassez ecológica está, portanto, afetando seriamente a gama inteira de setores econômicos, que são o alicerce do fornecimento alimentar humano (pesca, agricultura, água doce, silvicultura) e uma fonte crítica de sustento para a população carente. A escassez ecológica e a desigualdade social são marcas registradas de uma economia que está longe de se tornar "verde".

Outro fato preocupante na atualidade está relacionado ao crescimento da população em mais de $80 \%$ no Brasil, localizada em áreas urbanas, e isso implica maior consumo de energia e emissão de carbono, problemas de poluição, congestionamentos, emprego, saneamento básico e infraestrutura de modo geral, e, por não possuir tais condições de forma ideal para todos da cidade, a qualidade de vida é afetada, principalmente a vida da parcela da população mais pobre. Este é um fenômeno não só do Brasil, mas ocorre em escala global. Poucos países alcançaram elevado índice de desenvolvimento humano, porém possuem elevados índices de emissão de gases do efeito estufa, de modo que, certamente, esses países terão que reduzir as suas emissões e diminuir suas pegadas ecológicas per capita, sem alterar a sua qualidade de vida.

A definição de pegada ecológica, de acordo com a WWF (2013, online), consiste em uma metodologia de Contabilidade Ambiental que permite avaliar a demanda humana pelos recursos naturais renováveis, com a capacidade regenerativa da Terra. No Brasil, a pegada ecológica é em torno de 2,9 hectares por habitante. É variável a sobrecarga da pegada ecológica global entre os países, segundo informações do Relatório Planeta Vivo, da WWF (2014, online), pois, caso se praticasse o mesmo estilo de vida de uma pessoa dos Estados Unidos, seriam necessários 3,9 planetas. No caso de uma pessoa da África do Sul ou Argentina precisariam de 1,4 ou 1,5 planetas.

Existem os países que também possuem pequena pegada ecológica, e precisam se desenvolver de forma a proporcionar melhores condições de vida para a sua população. E como se desenvolver sem aumento drástico da sua pegada ecológica? Este é um desafio para a 
maioria das nações. No caso do Brasil, se está ainda muito distante de uma economia verde. Muitas medidas, no entanto, estão sendo adotadas, para uma economia esverdeada, por exemplo, o biodiesel, as energias renováveis (eólica, solar, marés, biomassa etc.), a reciclagem e reaproveitamento de materiais etc. Com relação às fontes de energias renováveis acentua Gomes (2010, p. 106) cumpre sublinhar que estas novas fontes de energia são devoradoras de espaço (torres eólicas, painéis fotovoltaicos, plantações de cana de açúcar) e não são inócuas nem do ponto de vista ambiental nem do ponto de vista social [..]. No Brasil, conforme 0 PNUMA (2011, online),

Aproximadamente $95 \%$ de todas as latas de alumínio e $55 \%$ de todas as garrafas de polietileno são recicladas. Cerca de metade de todo o volume de papel e vidro é recuperado. A reciclagem no Brasil gera quase US\$ 2 bilhões e evita a emissão de 10 milhões de toneladas de gases de efeito estufa na atmosfera. Apesar dessa façanha, materiais recicláveis no valor de US\$5 bilhões vão parar em aterros sanitários. A reciclagem completa desses materiais equivaleria a $0,3 \%$ do PIB.

A gestão da reciclagem no Brasil, no entanto, precisa se tornar eficiente e sustentável, considerando que os empregos na reciclagem de resíduos são compostos por uma maioria de pessoas que recebem rendas muito baixas, possuem péssimas condições de trabalho e estão inseridas no mercado informal. Não resta dúvida de que são indispensáveis políticas públicas, nos planos nacional e internacional, ao priorizarem uma economia que traga para as pessoas não só benefícios econômicos, mas, também, possibilite a vida com qualidade na dimensão ambiental, social e cultural. É necessário o desenvolvimento de tecnologias, que possibilitem maior eficiência e eficácia no uso dos recursos ambientais, investimento em educação de qualidade, políticas públicas ambientais, incentivos ambientais e mudanças de atitudes, como, por exemplo, de pensar, agir e interferir no meio ambiente. O paradigma do desenvolvimento sustentável, aliado ao crescimento econômico e à sustentabilidade, implicará um mundo com maior justiça social e ambiental, solidário para todos, inclusive para seus futuros habitantes.

\section{CONSIDERAÇÕES FINAIS}

Ao longo da pesquisa, ficou evidenciado o estabelecimento da crise ambiental em virtude da não preocupação humana com a natureza, do estabelecimento da visão e ação antrópica sem dimensionamento das consequências dos efeitos sobre o estoque de capital natural e o próprio homem. A solução encontrada no Relatório Brundtland para o prolongamento dos recursos ambientais foi o desenvolvimento sustentável como um novo paradigma que propõe a satisfação das necessidades atuais da população, considerando a dimensão social, econômica e ambiental do meio ambiente. 0 termo "desenvolvimento sustentável" surgiu na década de 1980, como nova ordem mundial, pois não basta crescer, sendo necessário que 0 crescimento econômico, seja sustentável, daí a importância de coadunação entre desenvolvimento sustentável e crescimento econômico. Logo, o desenvolvimento sustentável deve ter 
a participação da sociedade, e o planejamento territorial, visando ao equilíbrio entre a economia e o meio ambiente.

Na segunda Conferencia das Nações Unidas sobre M eio Ambiente, a Rio +10 , o princípio do desenvolvimento sustentável foi afirmado e, na Conferência das Nações Unidas para o Desenvolvimento, a RIO + 20, foi reafirmado e estabelecido como um dos objetivos do milênio. Não resta dúvida de que o desenvolvimento sustentável pressupõe mudanças duradouras na economia e na sociedade, na solução dos desafios atuais, e precisa ser levado a sério por setores públicos e privados e pela sociedade como um todo. Como alcançar, porém, 0 desenvolvimento sustentável? Como alcançar a sustentabilidade? Eis uma resposta difícil de oferecer, porque, para atingir a esses objetivos, uma série de mudanças, transformações e investimentos em educação de qualidade, tecnologias, saúde, emprego, renda, qualificação da mão de obra e infraestrutura precisa ser implementada com urgência em escala global, 0 que não é nada fácil.

No Brasil, a Constituição Federal de 1988 ao tratar do meio ambiente e da ordem econômica, estabeleceu o Princípio do Desenvolvimento Sustentável, sendo também reconhecido na legislação infraconstitucional. O Princípio da Solidariedade está expresso no Texto Constitucional como fundamento do Estado Democrático de Direito, justificando, assim, a finalidade do Direito Ambiental e coadunado com a proposta do Direito intergeracional.

A solidariedade intergeracional é responsabilidade da sociedade de hoje para com as futuras gerações. Consiste em um valor ético imensurável e num direito justo, pautado na expressão da Justiça Ambiental. 0 princípio da solidariedade ou equidade Intergeracional, na acepção de Silva (2011, p. 124), "decorre do reconhecimento constitucional e internacional do direito das futuras gerações ao meio ambiente ecologicamente equilibrado e, portanto, a imposição a todos, seja ao Estado, seja à coletividade, do dever de garanti-lo". Nesta perspectiva, a Justiça Ambiental busca um tratamento justo e igual para todas as pessoas, o direito de viver um ambiente limpo e saudável, com qualidade de vida de forma equânime.

A economia verde no contexto do desenvolvimento sustentável foi abordada, mostrando-se a necessidade de mudança de paradigma, ou seja, da forma convencional para a economia verde. A eficiência no uso dos recursos naturais pela economia verde é imprescindível e está relacionada ao estabelecimento de padrões e limites no uso dos recursos ambientais, como também, ao emprego de recursos tecnológicos e planejamento territorial para alcançar maior eficiência. Foi demonstrado que o Brasil possui vários exemplos de economia verde, como as fontes renováveis de energia, a reciclagem de materiais, os biocombustíveis etc. Mudanças estratégicas de planejamento territorial, uma série de investimentos, incentivos, informações, bem como conscientização ambiental, educação de qualidade são, contudo, necessárias para se alcançar o ideal no País em termos de crescimento econômico e desenvolvimento sustentável.

Em suma, a busca pela sustentabilidade, desenvolvimento sustentável e a conciliação deste com o crescimento econômico levará tempo para ocorrer de forma satisfatória no Brasil e no M undo. Os dirigentes dos países possuem grande responsabilidade em estabelecer as condições necessárias para o enfrentamento dos problemas socioeconômicos em escala glo- 
bal, visando à sustentabilidade para as futuras gerações. 0 desafio do desenvolvimento sustentável, coadunado com o crescimento econômico, constitui um dos grandes desafios deste século.

\section{REFERÊNCIAS}

ACSELRAD, Henri (Org.) M ELLO, Cecília C. A; BEZERRA, Gustavo N. 0 que é Justiça Ambiental. Rio De Janeiro: Garamond: FASE, 2009. Em: বhttp://www.ucs.br/site/midia/arquivos/JUSTI CA_AM BIENTAL_EDUCS_EBOOK.pdf>Acesso em: 28 ago. 2014.

BECKER, Dinizar Fermiano. A contradição em processo: o local e o global na dinâmica do desenvolvimento regional. Em BECKER, D. F.: WITTM ANN, M . L (orgs). Desenvolvimento regional: abordagens interdisciplinares, 2. ed. Santa Cruz do Sul: Edunisc, 2008.

BRASIL. Supremo Tribunal Federal. M edida Cautelar na Ação Direita de Inconstitucionalidade: ADI-M C no 3540 DF. DJ 03-02-2006. Relator ministro Celso de M ello. Disponível em: বttp:// stf.jusbrasil.com.br/jurisprudencia/763322/ medida-cautelar-na-acao-direta-de-inconstitucionalidade-adi-mc-3540-df $>$. Acesso em 15 Nov. 2014.

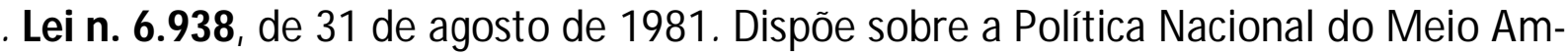
biente, seus fins e mecanismos de formulação e aplicação, e dá outras providências. Disponível em:<http://www.planalto.gov.br/ccivil_03/leis//6938.htm>Acesso em 20 set. 2014.

BUARQUE, Sérgio. C. Construindo o desenvolvimento local sustentável: metodologia de planejamento. Rio de Janeiro: Garamond, 2002.

COMISSÃO M UNDIAL SOBRE M EIO AM BIENTE E DESENVOLVIMENTO - CM M AD. Nosso futuro comum. 2. ed. Tradução de "Our common future". 1988. Rio de Janeiro: Editora da Fundação Getúlio Vargas, 1991.

COSTA, Beatriz Souza. Meio ambiente como direito à vida: Brasil, Portugal e Espanha. Belo Horizonte: Editora O Lutador, 2010.

DANTAS, Thiago Braga. Decrescimento econômico: a natureza como limite do crescimento e o novo contexto da economia verde. In: Sustentabilidade ambiental [recurso eletrônico]: estudos jurídicos e sociais. CUNHA, Belinda Pereira da, AUGUSTIN, Sérgio (Orgs). Dados Eletrônicos - Caxias do Sul, RS: Educs, 2014.

DECLARAÇÃO DA CONFERÊNCIA DAS NAÇÕES UNIDAS SOBRE MEIO AMBIENTE HUMANO. 1972. Declaração de Estocolmo. Disponível em: 〈http://www.apambiente.pt/_zdata/Politi cas/DesenvolvimentoSustentavel/1972_Declaracao_Estocolmo.pdf>. Acesso em: 15 Nov. 2014.

DECLARAÇÃO DO RIO SOBRE MEIO AM BIENTE E DESENVOLVIMENTO. 1992. Declaração do Rio de Janeiro sobre Meio Ambiente e Desenvolvimento. Disponível em: $h t t p: / / w w w . s c i e$ lo.br/pdf/ea/v6n15/v6n15a13.pdf>. Acesso em: 03 Jan. 15.

FIORILLO, Celso Antonio Pacheco. Curso de Direito Ambiental brasileiro. 12 ed.rev. atual e ampl. São Paulo: Saraiva, 2011.

GOM ES, Carla Amado. Os biocombustíveis na União Europeia: uma outra natureza da natureza. In: Actas do Colóquio Ambiente \& Energia. GOMES, Carla Amado; ANTUNES Thiago 
(Orgs.). Instituto de Ciências Jurídico-Políticas. Lisboa, 2010.

HARGRAVE, Jorge; PAULSEN, Sandra. Economia verde e desenvolvimento sustentável. In: Desenvolvimento sustentável, economia verde e a Rio + 20 - Relatório de Pesquisa. Brasília. Instituto De Pesquisa Econômica Aplicada (IPEA), 2012.

HANSEN, Gilvan Luiz. M odernidade, utopia e trabalho. Londrina. Ed. CEFIL, 1999.

INSTITUTO DE PESQUISA ECONÔM ICA APLICADA (IPEA). Desenvolvimento sustentável, economia verde e a Rio +20 - Relatório de Pesquisa. Brasília, 2012.

HENZ, Bruno Gabriel; PAULITSCH Nicole da Silva; CARDONE, Rachel dos Reis. As políticas ambientais em perspectiva histórica e seus impactos sobre as questões econômicas e jurídicas. In: Direito, economia e meio ambiente [recurso eletrônico]: olhares de diversos pesquisadores. RECH, Adir Ubaldo, BUTZKE, Alindo; GULLO, Maria Carolina (Orgs.). Dados eletrônicos Caxias do Sul, RS: Educs, 2012.

KRONEM BERGER, Denise. Desenvolvimento local sustentável: uma abordagem prática. São Paulo: Editora Senac. 2011.

LONDRES, Flávia. 0 mapa da injustiça ambiental. Carta Capital. Disponível em: বhttp://www. cartacapital.com.br/sociedade/ mapa-da-injustica-ambiental>. Acesso em: 06 Jan. 2015.

MILARÉ, Édis. Direito do Ambiente: doutrina, jurisprudência, glossário. 8. ed. São Paulo. Editora Revista dos Tribunais, 2013.

M ILLER, G. Tyler. Ciência ambiental. Tradução All Tasks. São Paulo. Thomson, 2007.

MORIN, Edgar, TERENA, Marcos. Saberes globais e saberes locais. 3. ed. Trad. Paula Yone Stroh. Rio de Janeiro: Garamond, 2001, p. 9.

NUSDEO, Fábio. Curso de Economia: introdução ao direito econômico. 4. ed. São Paulo, Revista dos Tribunais, 2005.

PEARCE, D.; MARKANDYA, A.; BARBIER, E. Blueprint for a green economy. Earthscan Publications, Londres, 1997.

PEPPER, D. (1996). Modern environmentalism. An Introduction. Routledge, Londres.

PINHEIRO, Maurício M ota Saboya. Desenvolvimento sustentável e economia verde: uma proposta de análise conceitual. In: Desenvolvimento sustentável, economia verde e a Rio + 20 Relatório de Pesquisa. Brasília. Instituto de Pesquisa Econômica Aplicada (IPEA), 2012.

PROGRAM A DAS NAÇÕES UNIDAS PARA O M EIO AM BIENTE (PNUM A), 2011. Caminhos para - Desenvolvimento Sustentável e a Erradicação da Pobreza - Síntese para Tomadores de Decisão. Disponível em <www.unep.org/greeneconomyPNUM A>. Acesso em 06 Jan. 15.

QUEIRÓS, Margarida. Questões para uma agenda contemporânea do desenvolvimento sustentável. Revista da Faculdade de Letras - Geografia. I série, vol. XIX, Porto, 2003, pp. 331343.

RAM ME E, R. S. Da justiça ambiental aos direitos e deveres ecológicos [recurso eletrônico]: conjecturas políticos-filosóficas para uma nova ordem jurídico-ecológica. Dados eletrônicos. Caxias do Sul, RS: Educs, 2012. Disponível em: বttp://www.ucs.br/site/midia/arquivos/JUSTI CA_AMBIENTAL_EDUCS_EBOOK.pdf>Acesso em: 05 Jan. 2015.

REÉS, J. (1992). $\bar{M}$ arkets - The Panacea for Environmental Regulation? Geoforum, 23 (3), pp. 383-384. 
REDCLIFT, M. (1993). Environmental economics, policy consensus and political empowerment. In: K. Turner. Sustainable environmental economics and management. Bethavem Press. Londres, pp. 106-119.

RODRIGUES, Isabel Nader. Desenvolvimento sustentável. In: Direito, economia e meio ambiente [recurso eletrônico]: olhares de diversos pesquisadores. RECH, Adir Ubaldo, BUTZKE, Alindo; GULLO, M aria Carolina (Orgs.). Dados eletrônicos. Caxias do Sul, RS: Educs, 2012.

ROMEIRO, Ademar Ribeiro. Desenvolvimento sustentável: uma perspectiva econômicoecológica. Revista Estudos Avançados 26 (74), 2012.

SACHS, Ignacy. Caminhos para o desenvolvimento sustentável. In: STROH, Paula Yone, (Org.). Rio de Janeiro: Garamond, 2002.

2004.

Desenvolvimento: includente, sustentável, sustentado. Rio de Janeiro: Garamond,

SARDENBERG, Ronaldo M ota. Ordenação territorial e desenvolvimento sustentável. Folha de São Paulo. Caderno I. 24 de abril. 1995. p.1.

SILVA, Marcela Vitoriano e. 0 princípio da solidariedade intergeracional: um olhar do Direito para o futuro. Revista Veredas do Direito. Belo Horizonte, v.8, n. 16, p. 115-146, jul./ dez. 2011.

VEIGA, José Eli da. Desenvolvimento sustentável: o desafio do século XXI. Rio de Janeiro: Garamond, 2010.

WORLD WILDLIFE FUND (WWF). Pegada Ecológica: nosso estilo de vida deixa marcas no planeta. Textos e Edição: Geralda Magela (Comunicação WWF-Brasil). WWF-Brasil, Brasília, 2013. Disponível em: 〈tttp://www.wwf.org.br/informacoes/ bliblioteca/?35722/Cartilha-Pega da-Ecologica>. Acesso em: 06 Jan. 15.

. Planeta vivo. Relatório 2014. WWF-Brasil, Brasília, 2014. Disponível em: ঝttp://www. wwf.org.br/informacoes/bliblioteca/?35722/Cartilha-Pegada-Ecologica>. Acesso em: 06 jan. 2015.

Artigo recebido em 30 de maio de 2016.

Aprovado em 07 de fevereiro de 2017. 